\title{
Reducing Our Prison Population: Past Failures and New Approaches
}

\author{
Juan Marcellus Tauri ${ }^{1}$
}

\section{Background}

The following commentary is based on speaking notes from a University of Waikato public lecture given by the author in Tauranga, New Zealand on $5^{\text {th }}$ of December 2018.

\section{Introduction}

Earlier this year the Minister of Justice, Andrew Little announced the latest in a long line of reviews, taxpayer-funded summits and inter-agency, 'wholeof-government' projects stretching back to the late-1980s, all aimed in some form or other, at making the criminal justice system more 'safe' and 'effective'. Officially launched at a summit held in Porirua in August 2018, the aim of the latest review is to reduce New Zealand's prison muster by $30 \%$ over the next 15 years. And unsurprisingly, given our significant over-representation in prisons, a specific focus of the review is on identifying ways to significantly reduce Māori over-representation in the prison population. This commentary represents a modest offering in response to the current government's stated aim of making the justice system safer and more effective, and to reduce the prison muster, and it is based on two core arguments, namely that successive governments and the public service have failed to reduce offending and imprisonment and that successful solutions require community empowerment and government/public service accountability.

For decades the policy sector, in support of the political class, has led the development and implementation of responses to crime in Aotearoa New Zealand. And the impact of their crime control activity has been mixed at best, with as many failures (if not more) as successes. However, regardless of the many failures, the over-reliance on importing crime control policies from high-crime jurisdictions and the Eurocentric bias of its policy

\footnotetext{
${ }^{1}$ The University of Waikato, New Zealand
} 
development processes, reform of the policy sector, and the political context of crime control policy are essential if Minister Little and the Coalition government is to meet its target of $30 \%$.

Any attempt to reduce the prison population requires a significant increase in the role of communities, especially service providers, in the development of responses to social harm. This process must be presaged with a reduction of the authority of the political class and public service in the development of crime control policy and a significant increase in their accountability to the taxpayer.

Case studies will be used throughout the commentary to highlight some of the reasons why the political class and public service have failed to reduce New Zealand's rate of imprisonment, especially of Māori. They are also used to support the argument that a meaningful reduction in the country's prison muster requires a significant overhaul of the policy sectors policy process, a necessary reduction in the influence of moral entrepreneurs such as the Sensible Sentencing Trust, and the political class's use of crime control as a means of creating fear, and votes, across the community.

\section{Catastrophic Failure and Crime Control Policy in New Zealand}

\section{Case Study 1 - The Department of Corrections Integrated Offender Management Programme}

When the author arrived at the then Department of Corrections in early 2001, officials were rolling out Integrated Offender Management (IOM). Imported more-or-less wholesale from Canada, IOM was, in theory at least, designed to streamline management of inmates' custodial sentences. In particular, it was meant to ensure the effective and efficient delivery of interventions to offenders that matched their identified 'criminogenic needs', those key drivers of their offending (according to the underlying theoretical framework known as the Psychology of Criminal Conduct) such as alcohol and drug dependency, anger management issues and cognitive impairment. Although touted as a new, scientific, empirically based response to offending, the importation and implementation of IOM provides a case study that encapsulates significant issues with the development of crime control policy in New Zealand, including: 


\section{The Superficiality of Public Service Consultation}

It was evident during both the policy development and implementation phases that senior management at Corrections was hell-bent in introducing the process despite a lack of evidence of efficacy of either the policies or criminogenic interventions (their suitability) for the New Zealand context, or dissenting views from staff and/or the public, especially from Māori. The 'implementation at any cost' ethos was most apparent in the internal and external 'consultation' exercises carried out by designated officials, called the 'IOM Champions'. The author was present at a number of consultations with staff and community members; overall the exercises were superficial, tick-the-box exercises where the concerns of participants were re-written in a final report to suit the pre-determined policy parameters of IOM or ignored altogether. And in some instances, despite assurances that staff could speak confidentially during internal consultation, staff who asked critical questions of IOM were reported to their managers who 'corrected' their behaviour.

\section{Orientalisation of Crime Control Policy Responses}

The importation and implementation of IOM by the department involved a liberal use of what Harry Blagg (via Edward Said) called the orientalisation of the crime control policy context. The process of orientalisation in crime control, as described by Blagg, refers to the strategy of dismissing criticisms of the cultural appropriateness of interventions, by drawing comparisons between disparate groups, in this case Black Canadians (for whom it was claimed IOM 'worked') and Māori, and arguing because it 'worked' for Black Canadians then it would work for Māori. The basis of this claim being that both groups were minorities and over-represented (and implicitly because both are 'coloured'). Missing from this argument was any evidenced analysis of the vastly different historical, socio-economic and intersectional drivers of the marginalised status of both communities. Orientalised comments were often used by the 'IOM Champions' (yes, an actual position!) within Corrections, when responding to concerns expressed by Maori staff within the department and external officials from Te Puni Kokiri, about the effectiveness of IOM for responding to the specific needs of Maori 
The Mythology of Evidence-Based Policy Processes

The IOM case study problematizes claims by the crime control sector that follows the principles of evidence-based policymaking when developing policies and interventions. A few years after the implementation of IOM and its suite of criminogenic interventions, time came for the analysis and release of the first tranche of outcome-based data, meaning the impact of the programmes on recidivism. The results were not what the Department had predicted. For some interventions, such as the cognitive programme Straight Thinking, Māori who did not attend had lower recidivism rates than those who did. The report was suddenly taken from the primary author to be 'edited', due to the poor results of the programmes in terms of impact on recidivism.

Despite evidence that the programmes, especially Straight Thinking, were not reducing offending, there was no consideration by the Department to cease using the interventions or significantly overhauling them. Officials responded to the poor outcome of their criminogenic programmes by claiming that all that was required was a little 'tweaking' to ensure their efficacy. Not long after the Department used the results of formative evaluations on community-centred programmes, as the basis of a decision to cease funding some. The same 'standard' of outcomes and impact was not applied to their own programmes.

Such behaviour is not uncommon in other agencies. The lessons from this example include firstly, agencies will use 'evidence' of effectiveness from programmes implemented in other jurisdictions, ignoring the impact of local conditions', and secondly, when evidence of programmatic failure arises, as it did with the IOM-related interventions in the mid-2000s, the sector applies quite different rules when considering continued support and funding for its favoured programmes in comparison to community-centred initiatives.

The implementation of IOM highlights several failings across New Zealand's criminal justice sector, explaining the low impact it has on crime rates and for reducing the prison muster, namely:

1. The sectors reliance on importing crime control policies and interventions from other high-crime, Western jurisdictions at the expense of home-grown solutions.

2. Retrofitting crime control policies and processes to the New Zealand context without the requisite engagement and research work required to ensure they 'fit' the New Zealand context. 
3. An aversion by the major criminal justice agencies to admit mistakes and release information that does not portray them in a good light.

4. And finally, an unwillingness, or inability to trust 'the community' to take the lead in the developing and delivering effective responses to social harm.

The rise of IOM coincided with a revolution within many of the crime control agencies wherein 'science' and 'evidence' became the basis of policymaking, the development of interventions, and allocation of resources. At least that is what the policy sector told itself and the public from the early 2000s onwards in numerous policy statements, annual reports and such like. Quite often this was not the case, with pertinent evidence being totally ignored or the evidence that suits a predetermined policy outcome favoured over the messy stuff, like evidence that contradicts a Cabinet Minister's pet project, or that highlights the negative impact of government's social and economic policy.

\section{Case Study - Boot Camps}

A recent example of policy implementation that ignored available evidence was the previous National government's (2008-2017) decision to introduce boot camps as a response to youth offending. At the time of implementation, no firm evidence existed that the intervention would result in positive outcomes for youth, but it was implemented regardless.

To understand how such a poorly performing crime control intervention could be introduced, one need to critique the oft-repeated claims that New Zealand's policy sector is apolitical (as in neutral) and policy decisions are based on scientifically derived evidence. This is often not the case in the crime control policy sector. The introduction of boot camps was purely ideological and political, a result of the political classes preference for the vote-winning 'tough on crime' approach to social harm. A nod to the 'a good thrashing never did me any harm' approach to crime control popular amongst radio shock jocks and other moral entrepreneurs.

To their credit, at the time Cabinet was considering the policy options for the camps, Ministry of Justice officials provided their Minister with a thorough written briefing that highlighted the lack of evidence that the intervention would, in fact, reduce youth offending. The Minister moved forward with the policy, simply noting that he had 'received, but not read' the briefing. Let me repeat that, he had received but not read the briefing. I will come back to this 'attitude' soon. 
I wish to be clear about one thing, sometimes evidence plays a significant role in policy development and implementation. My argument here is that sometimes it does not. The policy process can be, and often is, highly political and ideological, with interventions and policies influenced as much by who a Minister was drinking with last week, as it is on independent, empirical evidence.

Through this case study, we see the impact on crime control policy, of political ideology, of the need to secure votes, resulting in taxpayer's money being squandered on a failed intervention. Through this example, we observed political decisions being made in the face of overwhelming evidence that contradicts the political and ideological rationale offered by government. But it is not only the political class that is guilty of what is best described as policy-based evidence, as opposed to evidence-based policy, which can be defined as: Crime control policy based on the ideological and theoretical bias of the Policy Industry and politicians.

\section{What is the Crux of the Problem? The Policy Bubble!}

There are several issues/factors that play a role in the overall poor quality of policies and interventions produced by the Policy Industry. Combined they result in what I refer to as the Policy Bubble, a thin, protective rhetorical veil that results in officials making exaggerated claims of success in the face of the inevitable, catastrophic failure of existing or new policies and interventions.

How exactly does the bubble manifest in the policy context that is supposedly 'scientific' and politically neutral? Through planned, purposeful build-up of pressure relating to moral panic and political rhetoric relating to a particular social harm and/or a particularly problematic population (such as Māori or refugees). Supported by the utilisation of managerialist policy development tools underpinned by core procedural concepts (which are in fact meaningless rhetorical devices) like 'international best practice', 'evidence-based policy' and 'scientific interventions'. Underpinned by the cherry-picking of empirical evidence by policy workers to support preconceived, politically driven policy, resourcing and legislative decisions. All this activity is carried out with the full knowledge of the Policy Industry that the efficacy of said policies and interventions will have little positive impact on the crime rate and prison muster, especially for Māori - the exaggeration of its impact is intentional. 


\section{Bursting the Bubble}

Catastrophic policy failure occurs in New Zealand's crime control policy sector because of:

- an over-reliance on importation of interventions ill-suited to the Aotearoa New Zealand social context;

- the a-cultural, a-theoretical nature of policymaking that results in policies and interventions ill-suited to Māori and Pasifika peoples;

- a public service focused on 'political service' rather than serving the crime control needs of communities, and

- ignorance of contemporary lived experience/social context of Māori and 'other' communities and focus on 'consultation' rather than meaningful engagement.

And perhaps more importantly:

- exaggerated claims of policy efficacy are made in the face of inevitable, catastrophic failure because of the political nature of policymaking, and because policy development is about control and manipulation of individuals and populations and not the reduction of social harm.

\section{Strategies for Reducing the Prison Population}

In the last section of this commentary, several policy and 'political' responses will be offered that could assist Minister Little and his officials to reduce the prison muster but more importantly ensure that the reduction is sustainable over time.

\section{Response One - Depoliticise Crime Control Policy}

The first response appears on paper the easiest to implement, but, in fact, is probably the most difficult because it requires the political class to put aside their commitment to set ideological positions on crime control. Quite simply, New Zealand needs to depoliticise crime control policy similar to how Finland has done. We need a cross-party agreement to stop the nonsense where every three years politicians try to outdo each other to see who can appear the 'toughest on crime', promising (and often delivering) significant increases in police numbers (with the usual unrealised promises of reductions in crime), more prison beds, longer sentences, and so forth. This has been the standard political response to crime in New Zealand for the best part of three decades: has it made us safer, or, more accurately, to 'feel' safer? The answer is no. The way forward is to develop a policy process 
based on the needs of community, and one less concerned with the ballot box needs of politicians.

\section{Response Two - Get Over the Policy Cringe}

Those who work with victims and offenders invariably know what is needed to respond meaningfully to the issues that arise from social harm. We need the policy sector to work with both providers and communities more directly (and respectfully), to work with them as partners to develop effective, socially grounded programmes. In order to achieve this, we need to get over the policy cringe that too often afflicts the crime control policy sector.

Much like the cultural cringe, the policy cringe is based on the erroneous belief that 'things are done better elsewhere' and that successful responses to social harm must be imported from other jurisdictions, usually from jurisdictions with high crime rates! And so, we import crime control policies from other jurisdictions, invariably do little to alter them for the New Zealand context, and then place them over the top of community-centred practice... and watch them crash and burn. The classic example of this process was the importation to New Zealand in the mid-2000s of MultiSystemic Therapy (MST) from the US as part of the new youth residential programme that was trialled in Hamilton. Officials from several agencies, including Te Puni Kokiri (Ministry of Māori Development) stated serious concerns at the suitability of the programme for Māori youth; concerns that were ignored. The result? The programme, MST especially, failed to respond to the needs of youth offenders, especially Māori, while - at the same time a number of existing home-grown wrap-around, social support programmes for Māori youth, were ignored.

Response Three - Treatment and Social Support, Not Criminalisation and Imprisonment

There is a simple response that will reduce the prison population quickly and enable Minister Little to meet his 30\% objective... stop sending people to prison. Stop arresting people, charging them, sending them to court, sentencing them to imprisonment for victimless crimes, low-level drug offences, and so-called 'administrative crimes' and non-payment of fines. Stop sending people to prison who are addicted to drugs and alcohol, as well as those who have mental health issues. Instead, put more resources into 
social support and treatment and increase significantly the use of therapeutic jurisprudence.

And here is a suggestion that will likely anger some, and that is for the policy sector and the wider community to recognise the reality we are dealing with regarding our prison muster: a significant number of them are addicted, are mentally unwell, and many have long histories of trauma, in particular, domestic violence and sexual victimisation. If we want to stop them victimising others, we need to work with them so they can deal with their own trauma.

Alluding to the trauma of offenders is unpopular for some and brings forth comments like 'you are making excuses for serious crime': no, I am not. I am highlighting a reality that we need to deal with if we are to create a safer, more just society. It is an explanation of their behaviour and not a reason to ignore the harm they have caused others.

\section{Response Four - Let Us In!}

The crime control sector needs to grow up and become less concerned with image politics. It needs to stop being so risk-averse and allow independent researchers to undertake critical, independent research on all aspects of the criminal justice system. The principal crime control agencies have, for some time now, been making it very difficult for independent, critical researchers to scrutinise the performance of the 'system'.

We are talking here about the strategy, that a number of justice sector representatives have followed the past few years, of blocking research that does not suit their needs or could possibly result in critical analysis of their performance. And it is blocking independent researchers from going about their business, by using excuses like the information that will be gathered doesn't match with our trending data' or 'with the Department's strategic priorities'. And if that fails, Corrections, New Zealand Police and the Ministry of Justice fall back on well-worn excuses such as potential 'safety' issues for both inmates and researchers.

And yet other comparable jurisdictions, most notably the United Kingdom and Australia, regularly allow researchers to enter prisons to carry out independent work or engage in research with justice 'clients' to an extent not seen in the New Zealand context. The evidence for this is the significant amount (comparatively speaking) of independent research materials published in academic journals on prisons and corrections policies in that and other comparable jurisdictions. The problem in the New Zealand context 
seems to grow from the intersection - a dangerous combination - of three factors: 1) a policy elite who appear to believe themselves beyond critique, 2) a policy elite who believe they are not answerable to the public, and 3) a policy elite supported by a political elite who share the same aversion to independent scrutiny.

Let me be even more frank, policy workers and government agencies do not always have the answers and, more importantly, because they are so close to their own work, they often can't see the wood for the trees. In other words, it is sometimes difficult for them to step back and critically analyse the impact or their work or identify the questions that need to be asked of the performance of the criminal justice system. Sometimes the questions and topics 'the community', which includes independent researchers, inmates, ex-inmates, inmates and ex-inmates' families, victims and service providers, believe are important will not match those of the policy sector. And sometimes the questions that are important to these individuals and groups are the right ones to be asking, the right ones to be researching. It is essential to remember, a government agency is part of the public service and derives its resources from the public purse. Therefore, it is time for policy practitioners to stop acting as though they are not answerable to the public.

Response Five - Admit that Bias and Racism Exist in the Criminal Justice System

The recent claim by the Police Commissioner that there is no racism in the police, that some officers have 'unconscious bias' is nothing more than a political ruse designed to ignore the fact that racism exists in the New Zealand police force, as it does in many other jurisdictions. The existence of racism and bias in police and other criminal justice institutions across Western jurisdictions is well-evidenced, including jurisdictions that we regularly compare ourselves to, such as Great Britain and Australia. What makes the Commissioner and his supporters believe our force is any different? Perhaps it is because they continue to believe in the myth that New Zealand has the best race relations in the world? Bias exists in our criminal justice system, and despite the best attempts to block independent research that I spoke of earlier, we do have empirical evidence that demonstrates its existence, starting with Moana Jackson's 1988 report, two MRL Research Group attitudinal surveys in the 1990s, Roguski and Te Whaiti's Police Perceptions of Māori research published in 2000, and most recently, research by the Otago School of Medicine (published in 2018). 
If Māori are to take up the challenge to do more, as we should, then just as importantly, crime control institutions and the policy sector in New Zealand need to be more open and honest about the bias and racism that exists in our institutions and do something concrete about these issues. And if they do, perhaps then, together, we can change the landscape of criminal justice in this country, and Minister Little can meet his 30\% target. 